\title{
Lung function in young adults: evidence for differences in the chronological age at which various functions start to decline
}

\author{
S HURWITZ, JANE ALLEN, ARLETTE LIBEN, AND MARGARET R BECKLAKE
}

From the University Clinic, Department of Medicine, Royal Victoria Hospital and Department of Epidemiology and Health, McGill University, Montreal, Quebec, Canada

ABSTRACT In order to gather prospective information on the chronological age at which lung functions start to decline, follow-up measurements were carried out on 38 young adults (30 men and eight women) whose respiratory and cardiac function had been studied previously in the course of a survey of high school students. In the 15 subjects who had reached adult height at the time of the first study, only the vital capacity showed no change between studies, while forced expiratory flow rates $\left(\mathrm{FEV}_{1}, \mathrm{MMEF}\right)$, transfer factor (TLCO) and alveolar volume $\left(\mathrm{VA}_{\mathrm{A}}\right)$ all decreased. By contrast, in the 23 subjects who had grown in stature since the previous tests, there was an increase in the slow and forced vital capacity, no consistent change in FEV 1 and MMEF, and a decrease in TLCO. The findings are consistent with the view that the age-related decline does not start at the same chronological age for all lung functions, and suggest that structural changes associated with biological "aging" affect some functions before others. The results also illustrate the inadequacy of predicting values for early adulthood by backward extrapolation from later decades or forward extrapolation from the teens, and underline the need for comprehensive studies to elucidate the pattern of change which accompanies growth, maturation, and early adulthood.

For the most part our concepts of how lung functions "age" have been derived from crosssectional studies of populations spanning an appropriate age range, usually $20-80$ years, ${ }^{1-5}$ with events in early adulthood being assessed by backward extrapolation from later decades or forward extrapolation from the teens. ${ }^{1-6}$ However, a different picture emerges from studies in populations which span the periods of somatic growth, maturing, and aging. ${ }^{7-9}$ Thus there is gathering evidence ${ }^{89}$ that once somatic growth ceases, there is a period when some functions, such as vital capacity, ${ }^{7-9}$ continue to increase (the consequence, it is believed, of an increase in muscularity particularly of the shoulder girdle ${ }^{9}$ ), others such as peak flow rate $^{10}$ and transfer factor ${ }^{11}$ remain relatively stable, ${ }^{10}$ while yet others such as forced expiratory flow-rates low in the vital capacity decrease. ${ }^{8} 9$ Similar results were reported in a longitudinal study on

Address for reprint requests: Dr MR Becklake, Department of Epidemiology and Health, McGill University, 3775 University Street, Montreal H2W 1S6, Quebec, Canada. a cohort of medical students followed over 10 years. ${ }^{12}$

An opportunity to gather some prospective information on the age-related changes of lung function which occur after somatic growth ceases arose as a result of a previous study we had carried out on the growth of heart and lung function in teenage high school students. ${ }^{6}$ Seven to eight years had elapsed since the previous measurements so that all subjects were now older than 20 years of age. It was, therefore, decided to recall all subjects who could be traced for re-examination with the specific objective of determining the direction and magnitude of changes in lung functions of those subjects who had already attained their adult height at the time of the previous examination.

\section{Methods}

The original study had been carried out on a random sample $(n=168)$ stratified for sex, age, and height, of the approximately 1400 students currently attending an inner city high school in 
Montreal. ${ }^{6}$ One hundred and fifteen of the original sample were traced through the last address available in the school records and 18 of these had moved from Montreal; 39 attended for follow-up measurements. One subject who had developed asthma since leaving school was subsequently excluded, leaving 38 in the final analysis. The lung function results of these 38 subjects at the time of the first study were not different from those of the remainder of the original sample of the same sex, age, and height.

Subjects were examined by a respiratory symptom questionnaire, based on the British Medical Research Council questionnaire of 1966, and the following lung function tests: spirometry on a Stead-Wells spirometer, for measurement of inspired vital capacity (VCI), forced expiratory vital capacity (FVC), forced expiratory volume in one second $\left(F^{2} V_{1}\right)$, and maximal mid-expiratory flow rate (MMEF); single breath test for CO diffusion (TLCO) calculated from Krogh's diffusion constant $(K)$ and the alveolar volume (VA). Since our objective was comparison of the individual's results over time, we used exactly the same apparatus, calibrated in exactly the same way, and subjects performed the same number of tests in the same sequence, and followed the same procedures as before. ${ }^{6}$ To assess the possible effect of betweenreader differences in spirometry analysis, ${ }^{13}$ the technician who carried out the present tests reanalysed a set of 10 tracings from the original series - the mean and standard deviation of differences for $F V C, F E V_{1}$, and MMEF, respectively, $0.001( \pm 0.03), 0.001( \pm 0.04)$ and $-0.06 \mathrm{l} / \mathrm{s}( \pm 0.15)$, were minimal.

For the purposes of data analysis, subjects were divided into those who had not grown in height since the first study (group A: difference in height between tests $<2.5 \mathrm{~cm})$ and those who had (group B: difference in height between tests $>2.5 \mathrm{~cm}$ ). This criterion was selected to include the greatest decrease in height recorded $(-2 \mathrm{~cm})$ and presumably reflects errors in the measurement of height. Only those subjects who had not changed in height (group A) are relevant to the objective of the present study, which was to record changes in lung function once adult height has been achieved. However, results on subjects who had grown provided a check on procedure and measurement techniques, small changes of which may well have occurred over time despite our efforts to ensure comparability. Mean, standard error and $t$ statistic (mean/SE) were calculated for differences in lung functions between studies for groups $A$ and
B separately, and $\mathrm{p}$ values were multiplied bys? six, the number of $t$ statistics calculated for eacto group (Bonferroni adjustment). No adjustmenţ was made for interdependence of tests.

\section{Results}

Questionnaire data indicated a low prevalence of symptoms evenly distributed between group $\overrightarrow{\mathrm{E}}$ $A$ and B. No subjects reported cough, two spu tum, five dyspnoea on exertion, and sever wheezing. Two men, one in each group, weres currently engaged in occupations with a potentiado respiratory hazard (machine operator in a yaris mill, construction worker). Somewhat more thar half the subjects $(9 / 15$ in group $A$ and $11 / 23$ if group B) were current smokers.

Mean changes in the lung functions betwee the first and second studies are shown for the two groups in table 1. In boys who, for the purroses of the present study, were consideredo not to have grown between tests (group A) there was on average a small increase in $\mathrm{VCE}$ and a small decrease in FVC, MMEF, and VP but these changes were not significant. However? FEV $_{1}$ and TLco did show a significant decrease By contrast, in boys who had grown since the previous measurements (group B), there were significant increases of VCI and FVC of ape proximately 0.9 while the changes in all other

Table 1 Mean changes in body characteristics and lung functions between first and second studies in subjects who had not grown in height since first study (groupA) an\& subjects who had (group B)

\begin{tabular}{|c|c|c|c|c|c|}
\hline \multirow{2}{*}{$\begin{array}{l}\text { Body characteristics } \\
\text { and lung functions }\end{array}$} & \multicolumn{4}{|c|}{ Mean change since first study (range or SE) } & \\
\hline & \multicolumn{2}{|c|}{ Group $A$} & \multicolumn{2}{|c|}{ Group $B$} & \\
\hline $\begin{array}{l}\text { Boys } \\
\text { Age (yr) } \\
\text { Height (cm) } \\
\text { Weight (kg) }\end{array}$ & $\begin{array}{l}\mathrm{n}=11 \\
+7.0 \\
+1.5 \\
+3.4\end{array}$ & $\begin{array}{l}(6.4 \text { to } 8 \cdot 8) \\
(-.4 \text { to }+2.5) \\
-14.0 \text { to }+13.8)\end{array}$ & $\begin{array}{l}\mathbf{n}=19 \\
+7.0 \\
+7.9 \\
+11.4\end{array}$ & $\begin{array}{l}(6.6 \text { to } 7.8) \\
(2.7 \text { to } 25.0) \\
-9.4 \text { to } 23.0)\end{array}$ & \\
\hline $\begin{array}{l}\text { VCI (l) } \\
\text { FVC (1) } \\
\text { FEV } 1 \text { (1) } \\
\text { MMEF (1/s) } \\
\text { TLCO }(\mathrm{ml} / \mathrm{mm} / \mathrm{min}) \dagger \\
\text { VA }_{\text {A }} \text { ( }\end{array}$ & $\begin{array}{l}+0.13 \\
-0.19 \\
-0.31 \\
-0.51 \\
-6.4 \\
-0.88\end{array}$ & $\begin{array}{l}(0 \cdot 12) \\
(0 \cdot 10) \\
(0 \cdot 11)^{*} \\
(0 \cdot 23) \\
(1 \cdot 3)^{*} \\
(0 \cdot 45)\end{array}$ & $\begin{array}{l}+0.89 \\
+0.90 \\
+0.32 \\
-0.18 \\
-1.1 \\
+0.33\end{array}$ & $\begin{array}{l}(0.21)^{*} \\
(0.18)^{*} \\
(0.17) \\
(0.65) \\
(2 \cdot 0) \\
(1 \cdot 3)\end{array}$ & \\
\hline $\begin{array}{l}\text { Girls } \\
\text { Age (yr) } \\
\text { Height (cm) } \\
\text { Weight (kg) }\end{array}$ & $\begin{array}{l}n=4 \\
+6.9 \\
+0.1 \\
+2.5\end{array}$ & $\begin{array}{l}(6 \cdot 5 \text { to } 7 \cdot 8) \\
(-1 \cdot 3 \text { to }+\cdot 7) \\
(-.5 \text { to }+5 \cdot 2)\end{array}$ & $\begin{array}{l}\mathrm{n}=4 \\
+7 \cdot 5 \\
+5 \cdot 3 \\
+5 \cdot 1\end{array}$ & $\begin{array}{l}(6.6 \text { to } 8.8) \\
(3.0 \text { to } 9.5) \\
-0.8 \text { to }+16 .\end{array}$ & \\
\hline $\begin{array}{l}\text { VCI (l) } \\
\text { FVC (1) } \\
\text { FEV }(1) \\
\left.\operatorname{MMEF}_{1} / \mathrm{s}\right) \\
\text { TLCO(ml/mm/min)† } \\
\text { VA (l) }\end{array}$ & $\begin{array}{l}+0.12 \\
-0.11 \\
-0.46 \\
-0.75 \\
-1.8 \\
-0.35\end{array}$ & $\begin{array}{l}(0 \cdot 16) \\
(0 \cdot 11) \\
(0 \cdot 09)^{*} \\
(0 \cdot 10)^{*} \\
(2 \cdot 6) \\
(0 \cdot 29)\end{array}$ & $\begin{array}{l}+0.24 \\
+0.07 \\
+0.07 \\
+0.09 \\
-5.3 \\
+0.06\end{array}$ & $\begin{array}{l}(0 \cdot 18) \\
(0 \cdot 16) \\
(0 \cdot 16) \\
(0 \cdot 31) \\
(1 \cdot 5) \\
(0 \cdot 40)\end{array}$ & \\
\hline
\end{tabular}

* $<0.05$ (calculated using the Bonferroni adjustment, see text). $\dagger$ To convert from $\mathrm{ml} \mathrm{STPD} \mathrm{mmHg}^{-1}$ to mmol $\mathrm{kPa}^{-1}$ divide by 0.334 . 
Table 2 Lung functions (mean, $S A$ ) at the second study with subjects divided into those who had not grown in height (group A) and those who had (group B)

\begin{tabular}{|c|c|c|c|c|}
\hline \multirow{2}{*}{$\begin{array}{l}\text { Body charac- } \\
\text { teristics and } \\
\text { lung function }\end{array}$} & \multicolumn{2}{|l|}{ Boys } & \multicolumn{2}{|l|}{ Girls } \\
\hline & Group A & Group B & Group $A$ & Group B \\
\hline $\begin{array}{l}\text { Number } \\
\text { Age (yr) } \\
\text { Height (cm) } \\
\text { Weight (kg) }\end{array}$ & $\begin{array}{l}11 \\
25 \cdot 2(0 \cdot 39) \\
174 \cdot 8(1 \cdot 7) \\
74 \cdot 3(3 \cdot 3)\end{array}$ & $\begin{array}{l}19 \\
22 \cdot 8(0 \cdot 34) \\
174 \cdot 3(1 \cdot 8) \\
73 \cdot 1(2 \cdot 2)\end{array}$ & $\begin{array}{r}4 \\
24 \cdot 6(1 \cdot 1) \\
159 \cdot 8(0 \cdot 9) \\
54.4(2 \cdot 8)\end{array}$ & $\begin{array}{l}4 \\
21.6(0.25) \\
159.8(1.4) \\
52.8(3.5)\end{array}$ \\
\hline 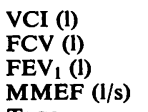 & $\begin{array}{l}4.95(0 \cdot 22) \\
5 \cdot 12(0 \cdot 21) \\
4 \cdot 23(0 \cdot 19) \\
4 \cdot 56(0.33)\end{array}$ & $\begin{array}{l}4.92(0.21) \\
5.15(0.22) \\
4.08(0.21) \\
4.11(0.25)\end{array}$ & $\begin{array}{l}3.31(0.23) \\
3.37(0.27) \\
2.55(0.09) \\
2.57(0.16)\end{array}$ & $\begin{array}{l}3.29(0.18) \\
3.39(0.19) \\
2.93(0.18) \\
3.44(0.40)\end{array}$ \\
\hline $\begin{array}{l}\text { TLCO } \\
\text { (ml/mm/min*) } \\
V_{A}(\mathrm{l})\end{array}$ & *) $\begin{array}{c}25.5(1.4) \\
5.76(0.94)\end{array}$ & $\begin{array}{c}26.5(1.4) \\
5.79(0.92)\end{array}$ & $\begin{array}{l}17 \cdot 6(3 \cdot 8) \\
4 \cdot 17(0 \cdot 71)\end{array}$ & $\begin{array}{c}14 \cdot 8(0.70) \\
4 \cdot 14(0.40)\end{array}$ \\
\hline
\end{tabular}

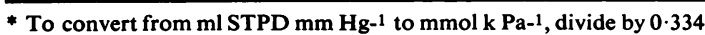

measurements were small and not statistically significant. The pattern of change was similar in the girls.

The numerical data from table 1 are shown graphically in the figure in which measurements for individual subjects at finst study are plotted against measurements at second study. For group A (open circles) it is only in the panel for VCI that points are equally distributed about the line of identity; for FVC approximately one-third only lie on or above the line, while for all other panels almost all points fell below the line of identity. The contrast with group B subjects (solid circles) is evident in all panels including TLco though for this panel both open and closed circles straddle the line of identity; nevertheless the open circles are distributed preferentially below this line. From table 2 it can be seen that at the time of the second study the mean values for the two groups were comparable for the body characteristics usually used to predict lung functions (height and weight) as well as for all the lung functions. In other words, group B subjects, who were first studied at a younger age and who therefore had grown more in height between tests, had become comparable to group A subjects not only in respect of body stature, but also in respect of lung functions.

\section{Discussion}

These findings provide further evidence that once adult height is reached, there are differences in the chronological age at which lung functions start to decline, and our findings are compatible with the view that vital capacity remains stable over an age span when forced expiratory flow rates (particularly those dependent on flow at low lung volumes) and the transfer factor have already started to decrease.

The evidence we advance is based on a comparison of the pattern of change over time in one lung function test vis à vis others in individuals identified by an independent characteristic-namely, failure to increase in height

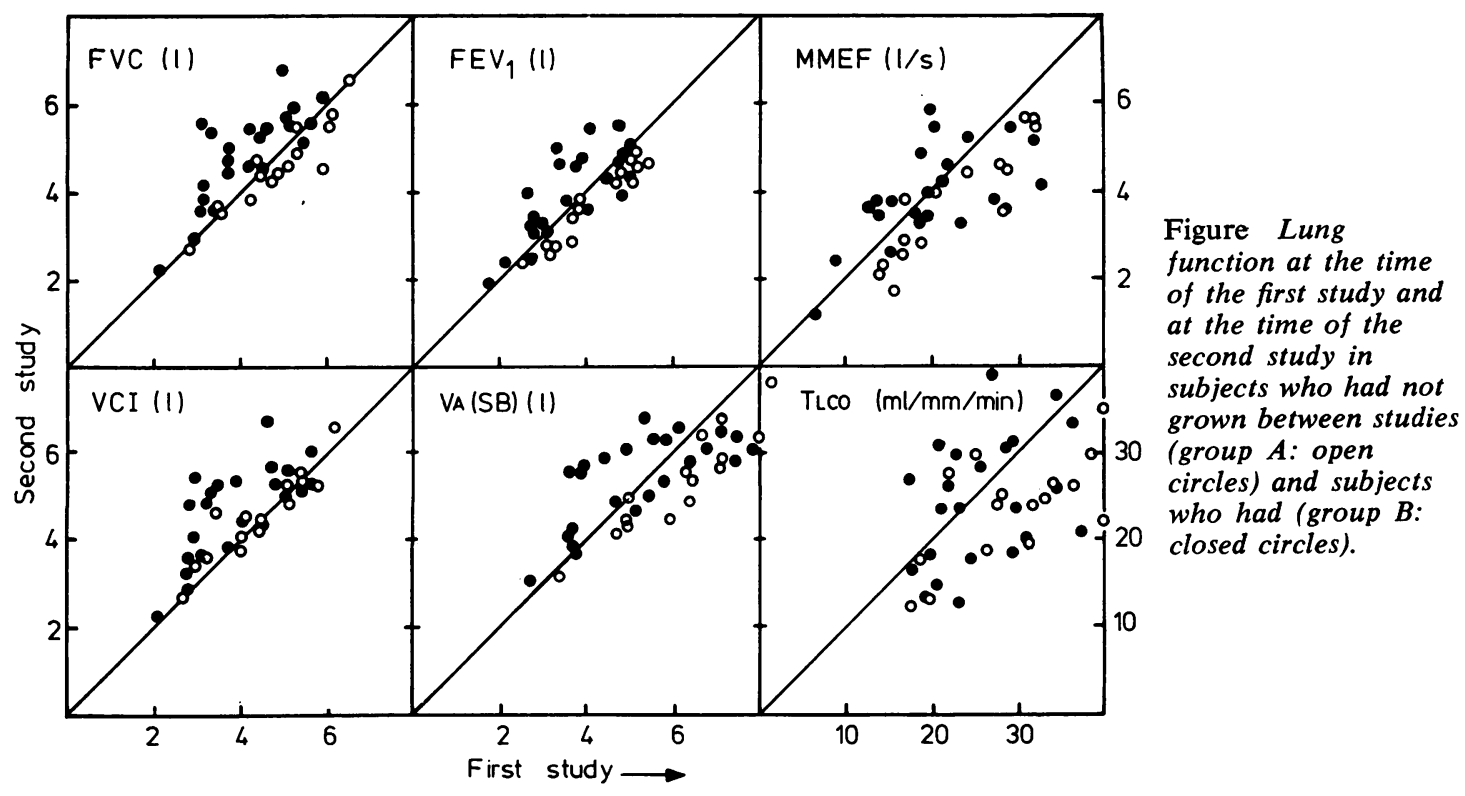


over the study period (group A). We also confirmed that this pattern was different from that in subjects who grew (group B), thereby diminishing the likelihood that the changes observed were solely the result of unsuspected changes in methodology. Smoking in all likelihood modified the changes over time but since equal proportions in groups A and B were current smokers, between-group differences in pattern of change should be valid. Furthermore, scrutiny of individual results did not reveal obvious differences between smokers and non-smokers. Finally, it is evident that the students we examined were not a planned sample of the group originally studied. However, since we were able to establish that when first examined their lung functions (the characteristics under study) were comparable to those of the original group of the same sex, age, and height, there is no reason to believe that the pattern of growth and maturation of these characteristics (a natural biological event) would have been essentially different in character or even in degree from those of the original sample not re-examined.

We did not show an increase in VC in the early twenties, in keeping with the original nineteenth century data of Hutchinson, ${ }^{14}$ as well as with some of the earlier twentieth century data. ${ }^{15}$ However, more recent data including two major cross-sectional studies ${ }^{89}$ and a recent one of our own concentrating on early adulthood $^{16}$ as well as the medical student cohort study, ${ }^{12}$ all refort a definite increase in this measurement in men (less evident in women) in the early twenties-that is, at an age when presumably somatic height has reached a stable level. This increase, associated with a weight increase, has been attributed to muscular development. ${ }^{9}$ In the present study, we may have missed this trend in the seven to eight years between measurements.

By contrast with the VCI and FVC, the forced expiratory flow rates, $\mathrm{FEV}_{1}$ and MMEF, showed a decline over the same period of time in our study, an observation in keeping with the reported cross-sectional data. ${ }^{8916}$ However, in these studies as well as in the present study, volume was recorded at the mouth, not using a body plethysmograph, and thus we cannot exclude the possibility of intrathoracic gas cempression contributing to, or perhaps accounting entirely for, the observed decline in forced expiratory flow rates, particularly if significant muscular development takes place in the early twenties. ${ }^{16}$ Alternatively, the decline may indeed be attributable to the onset of phenomen associated with biological "aging."

The decline in TLCO we observed is in keeping with the findings in the medical student cohos study, ${ }^{12}$ but contrasts with the findings in turb cross-sectional studies where age-related changes in TLCO were not evident before the thirties. ${ }^{11} \varphi_{T}$ It is more difficult to exclude the influence $\vec{P}$ technical factors in the measurement of $T_{L C}$ than, for instance, in the measurement of $V \Theta_{3}$ indeed in the second follow-up of the medic student cohort (average age 28 years) this measurement had again increased.12 In our stud So $_{0}$ the fall in TLCO was the consequence of if decline in $K$ as well as $V_{A}$ measured by the single breath helium dilution as part of the measurement. In the absence of plethysmographic measurements, it is not possible determine whether this decline in $V_{A}$ represent a true decline in inthrathoracic gas volume or, appears more likely, a decline in communicating lung volume, a possible concomitant of the increase in the level of airway closure known to occur between the teens and the twenties. ${ }^{18}$

The present results reinforce the point mad previously by ourselves ${ }^{16}$ and others ${ }^{9}{ }^{19}$ the simple linear regressions on age are inaccura for predicting values for the young adult and highlight the need for further study to defin $\overrightarrow{\vec{\theta}}$ the changes associated with growth and matura tion as well as early "aging" of lung functions. 倍 addition because the changes are not the same for all lung functions, the range of measurements for study should be at least as comprehensive used in our study. Thus lung volume measures ments should be included, preferably using bod plethysmography, in addition to static ang dynamic lung volumes and transfer factoo Indeed the development of accurate prediction formulae for young adulthood has more tham theoretical importance not only for routine lung function laboratories where the young an healthy are now far more frequently examineof particularly in relation to occupation, ${ }^{9}$ but als because of increasing attention directed to changes in lung function in early adulthood as reflection of earlier childhood events, ${ }^{20}$ or as predictor of future health problems. ${ }^{1}$

This study was supported by the Medicaf Research Council (MRC) of Canada, and MRBO is an MRC Associate. We are also much indebte? to Heberto Ghezzo for help in data analysis. Tho data were presented in abstract form at thg annual meeting of the Canadian Society of Clini cal Investigation ${ }^{21}$ in February 1979. 


\section{References}

1 Becklake MR, Permutt S. Evaluation of tests of lung function for "screening" ie for early detection of chronic obstructive lungs disease. In: Macklem PT, Permutt S, eds. The lung in the transition between health and disease. New York and Basel: Dekker, 1978: 345-87.

2 Cotes JE, Rossiter CE, Higgins ITT, Gilson JC. Average normal values for the forced expiratory volume in white Caucasian males. $\mathrm{Br}$ Med J 1966; 1:1016-9.

3 Kory RC, Callahan R, Boren HG, Syner JC. The Veterans Administration-Army Cooperative Study of pulmonary function. I. Clinical spirometry in normal men. Am J Med 1961; 30:24358.

4 Morris JF, Koski A, Johnson LC. Spirometric standards for healthy non-smoking adults. Am Rev Respir Dis 1971; 103:57-67.

5 Ferris BG Jr, Anderson DO, Zickmantel R. Prediction values for screening tests of pulmonary function. Am Rev Respir Dis 1965; 91: 252-61.

6 Seely JE, Guzman CA, Becklake MR. Heart and lung function at rest and during exercise in adolescence. J A ppl Physiol 1974; 36:34-40.

7 Berglund EG, Birath G, Bjure J et al. Spirometric studies in normal subjects. I. Forced expirograms in subjects between 7 and 70 years of age. Acta Med Scand 1963; 173:185-92.

8 Knudson RJ, Slatin RC, Lebowitz MD, Burrows B. The maximal expiratory flow-volume curve: normal standards, variability and effects of age. Am Rev Respir Dis 1976; 113:587-600.

9 Schoenberg JE, Beck GJ, Bouhuys A. Growth and decay of pulmonary function in healthy blacks and whites. Respir Physiol 1978; 33:367-93.

10 Brooks AGF, Waller RE. Peak flow measurements among visitors to a public health exhibition. Thorax 1972; 27:557-62.
11 Georges R, Saumon G, Loiseau A. The relationship of age to pulmonary membrane conductance and capillary blood volume. Am Rev Respir Dis 1978; 117:1069-78.

12 Lawther PJ, Brooks AGF, Waller RE. Respiratory function measurements in a cohort of medical students: a ten-year follow-up. Thorax 1978: 33:773-8.

13 Snider GL, Rieger RA, Demas T, Doctor L Variations in the measurement of spirograms. Am J Med Sci 1967; 254:679-84.

14 Hutchinson J. On the capacity of the lungs and on the respiratory functions, with a view to establishing a precise and easy method of detecting disease by the spirometer. Med Chir Trans (London) 1846; 29:137.

15 Bowen BD. The relation of age and obesity to vital capacity. Arch Int Med 1923; 31:579-89.

16 Rea H, Becklake MR, Ghezzo H, Allan J, Liven A. The influence of race and sex on the agerelated changes of lung function in young adults. Am Rev Respir Dis 1979; 119:350.

17 Hyland RH, Krastins IRB, Aspin N, Mansell AL, Zamel N. Effect of body position on carbon monoxide diffusing capacity in asymptomatic smokers and nonsmokers. Am Rev Respir Dis 1978; 117: 1045-53.

18 Mansell A, Bryan C, Levison H. Airway closure in children. J A ppl Physiol 1972; 33:711-4.

19 Anderson TW, Brown JR, Hall JW, Shephard RJ. The limitations of linear regressions for the prediction of vital capacity and forced expiratory volumes. Respiration 1968; 25:140-58.

20 Burrows B, Knudson RJ, Lebowitz MD. The relationship of childhood respiratory illness to adult obstructive airway disease. Am Rev Respir Dis 1977; 115:751-60.

21 Becklake MR, Hurwitz S, Ross J, Liben A. Lung functions in young adults: evidence for differential onset of aging. Clin Res 1978; 26: 876A. 